\section{A clinical evaluation of all-ceramic bridges placed in UK general dental practices: first-year results}

\author{
R. J. Crisp, ${ }^{1}$ A. J. Cowan, ${ }^{2}$ J. Lamb, ${ }^{3}$ O. Thompson, ${ }^{4}$ N. Tulloch ${ }^{5}$ \\ and F. J. T. Burke
}

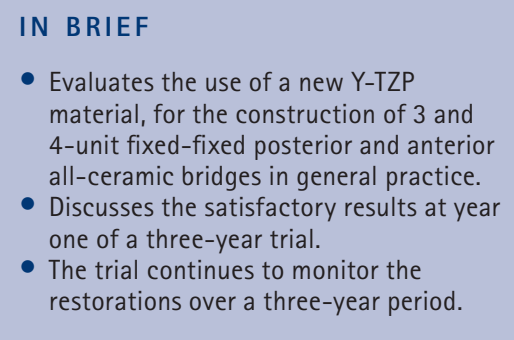

\begin{abstract}
Purpose To report the results at year one of a three-year evaluation of the performance of fixed all-ceramic bridges, constructed with a yttrium tetragonal zirconia polycrystal substructure placed in adult patients in UK general dental practices and cemented using a self-adhesive resin-based cement. Methods Ethical approval was obtained. Four UK general dental practitioners were asked to recruit patients complying with the trial criteria and protocol. After obtaining informed written consent, appropriate vitality and radiographic assessments were completed and the pre-operative status of the gingival tissues noted. The teeth were prepared and bridges constructed using the same technician and laboratory procedures. Each bridge was reviewed within three months of the anniversary of its placement by a calibrated examiner together with the clinician who had placed the restoration. The examiners evaluated the integrity of the restoration, its anatomic form, marginal adaptation, surface quality, sensitivity, the condition of the adjacent gingivae, and the presence or absence of secondary caries. Results All the bridges $(n=38)$ examined at the first-year review were present, intact and performing well, though one small chip of the veneering porcelain was detected and in two cases an abutment tooth had been endodontically treated through an occlusal access cavity.
\end{abstract}

\section{INTRODUCTION}

\section{Research in dental practice}

The majority of dental treatment, worldwide, is carried out in general dental practice so, if new techniques and materials are to be successful, it would seem logical that this environment should be the setting for clinical dental research. ${ }^{1}$ Arguments previously raised against research in dental practice have included the potential cost, the lack of research training of general dental practitioners and the uncontrolled nature of the work. ${ }^{2,3}$ However, the latter should be viewed as a strength - dental practice is the 'real world'. ${ }^{4}$ Clinical trials may be costly and the potential for some additional cost of practice-based studies as

\footnotetext{
1*,6Primary Dental Care Research Unit, University of Birmingham School of Dentistry, St. Chad's Queensway, Birmingham B4 6NN; ${ }^{2}$ General Dental Practice, Buxton; ${ }^{3}$ General Dental Practice, Liverpool; ${ }^{4}$ General Dental Practice, Coleraine; ${ }^{5} \mathrm{General}$ Dental Practice, Alness ${ }^{*}$ Correspondence to: Mr Russell Crisp Email:r.j.crisp@bham.ac.uk
}

\section{Refereed Paper}

Accepted 29 July 2008

DOI: 10.1038/sj.bdj.2008.937

${ }^{\circledR}$ British Dental Journal 2008; 205: 477-482 compared with research in academic institutions would be to cover:

1. The dental practice costs of carrying out the research

2. Any additional costs to the patient

3. The cost of trial coordinators/ assessors' time and travel to the dental practice.

Many recent graduates will have had some grounding in research methods in their curriculum, though this is variable. ${ }^{4}$ The value of research networks and groups has been recognised, and practitioners involved in research groups have considered it the best continuing education they have had. ${ }^{4,5}$ One such well-established group in the UK is the PREP (Product Research and Evaluation by Practitioners) panel, ${ }^{6}$ whilst in the US the Clinical Research Associates Foundation was founded over 30 years ago. In the PREP panel, of the 28 members, four are female and the average age since graduation is 21 years. The panel has a UK-wide distribution and 61\% of the members hold postgraduate degrees or diplomas. Since being founded, this group have completed and published the results of over 50 'handling' evaluations and three clinical trials. These trials were successfully concluded with high recall rates, and have been previously reported in peer-reviewed journals. ${ }^{7,8}$ The conduct of these clinical trials has built up an experienced team of general dental practitioners (GDPs), trained evaluators, and the provision of any required backup. Though one-year trials may produce valuable data on the potential for early catastrophic failure of restorations, both dentists and patients need to know need how new materials and techniques perform in the longer term. A threeyear, or longer, evaluation would provide more satisfactory information for all concerned.

\section{Yttrium tetragonal zirconia crystals} (Y-TZP) and CAD-CAM technology

Patients are increasingly requesting aesthetic restorations for both anterior and posterior teeth. ${ }^{9}$ Until recently, the majority of crowns and bridges were constructed using a metal substructure, ${ }^{10}$ covered by an opaque ceramic. This combination does not always produce optimal aesthetics and the possibility 
also exists of an allergic reaction to one or more of the metal alloys used in metal-ceramic restorations.

The adaptation of computer-aided design and manufacture (CAD-CAM) technology to the production of dental restorations in recent years has led to the introduction of a variety of dental CAD/CAM systems. One of the materials used in the industrial manufacture of ceramic components by CAD/CAM technology was a modified form of zirconium oxide $\left(\mathrm{ZrO}_{2}\right)$. Being both biocompatible and high strength it was first used in the heads in total hip replacement prostheses, ${ }^{11}$ and appeared to have almost ideal properties for use in the construction of cores for crowns and bridges. Pure $\mathrm{ZrO}_{2}$ has a monoclinic crystal structure at room temperature and transitions to tetragonal and cubic phases at increasing temperatures. On cooling from high temperatures the volume expansion caused by transformation back to the monoclinic phase induces very large stresses and can cause pure $\mathrm{ZrO}_{2}$ to fracture. The addition of 3\% yttrium oxide $\left(\mathrm{Y}_{2} \mathrm{O}_{3}\right)$ stabilises the tetragonal phase ceramic, and the material is then known as yttrium tetragonal zirconia polycrystals (Y-TZP). This material has the advantage of enhanced fracture toughness as when external stress is applied it is magnified by stress concentration at the crack tip, causing transformation of the existing configuration of the adjacent zirconia to another phase. The associated volume expansion places the crack tip in compression, retarding its growth - a mechanism known as transformation toughening. ${ }^{12}$

Possible disadvantages of Y-TZP ceramic materials are cost, opacity and loss of strength in a moist environment. With the material under investigation (Lava, 3M ESPE, Seefeld, Germany) the milled framework is stained after the milling stage and prior to sintering, with a dye which matches the final overlay ceramic, in order to overcome the inherent opacity of the white zirconia.

Curtis et $a l .{ }^{13,14}$ have reported laboratory experimentation which indicated that Lava discs stored in water at $37^{\circ} \mathrm{C}$ for 24 hours did not lose strength when compared with discs stored dry, and that grinding with fine diamond burs (20-40 micron) with water coolant also did not adversely affect strength. Sorensen ${ }^{12}$ has also demonstrated excellent in vitro marginal fit of this material and this has been confirmed clinically in clinical trials reported to date..$^{15,16}$

Though a variety of luting materials may be used for the cementation of Lava bridges the use of the self-adhesive resinbased luting material RelyX Unicem (3M ESPE, Seefeld, Germany) was considered particularly appropriate, being less technique sensitive than conventional resin-based luting materials as the need to etch or apply a bonding agent to the preparations is obviated. ${ }^{17}$ This luting material has also been demonstrated to have superior bond strength when used to lute restorations of the material under investigation..$^{18}$

\section{OBJECTIVE}

The purpose of this practice-based multi-centre observational study was to evaluate the three-year performance of all-ceramic bridges, constructed with a Lava substructure placed in adult patients in four UK general dental practices and cemented using a self-adhesive resin based cement (Rely X Unicem, 3M ESPE, Seefeld, Germany).

The primary end points of this investigation were:

- Retention of the restoration

- Lack of fracture of the restoration

- Margin integrity

- Secondary caries status

- Post-operative sensitivity.

With secondary end points:

- Health of gingival tissues surrounding the restored teeth

- Colour match

- Stain resistance

- Surface quality.

\section{ETHICAL STANDARDS}

The study was conducted in accordance with the Declaration of Helsinki (1964) as revised in Venice in 1983. Ethics Committee approval was obtained prior to commencing the study and informed written consent was obtained from all patients prior to registration for participation in the evaluation. Implicit in giving informed written consent was the right of patients to withdraw from the study at any time.
Table 1 Patient inclusion and exclusion criteria

To be considered appropriate for inclusion in the study a patient was:

- Over 18 years of age

- Had a molar supported permanent dentition free of any clinically significant occlusal interferences

- Had well maintained dentitions free of any active, untreated periodontal disease

- Had a maximum of two three or four-unit fixed/fixed bridges requiring placement

- Was a regular dental attender who agreed to return for assessments.

Patients were excluded from participating in the study if:

- There is a history of any adverse reaction to clinical materials of the type to be used in the study

- There was evidence of occlusal parafunction and/or pathological tooth wear

- They were pregnant or had medical and/or dental histories which could possibly have complicated the provision of the proposed restoration and/or influenced the behaviour and performance of the restorations in clinical service

- They were irregular dental attenders.

The abutment teeth included were in occlusal function and there was a valid reason for the placement of a bridge to replace the missing unit(s). The abutment teeth were free of signs and symptoms of periapical pathology both clinically and radiographically

Table 2 Criteria for baseline evaluation

Margin adaptation $0=0$ ptimal

1 = slight deficiency

Colour match $0=0$ ptimal, $1=$ Slight mismatch,

$2=$ Gross mismatch

Gingival health

Facial $11 \quad 2 \quad 3014$

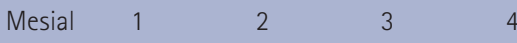

$\begin{array}{lllll}\text { Distal } & 1 & 2 & 3 & 4\end{array}$

Gingival status codes:

1. Healthy gingivae

2. Mild inflammation - slight color change, slight edema, no bleeding on probing

3. Moderate inflammation - redness, oedema and glazing, bleeding on probing.

4. Severe inflammation - marked redness and edema, tendency to spontaneous bleeding

\section{THE INVESTIGATORS}

Six investigators took part in this study - four UK general practitioners and two staff members of the University of Birmingham School of Dentistry.

\section{MATERIALS AND METHODS}

Four general dental practitioner members of the PREP panel (mean time since 


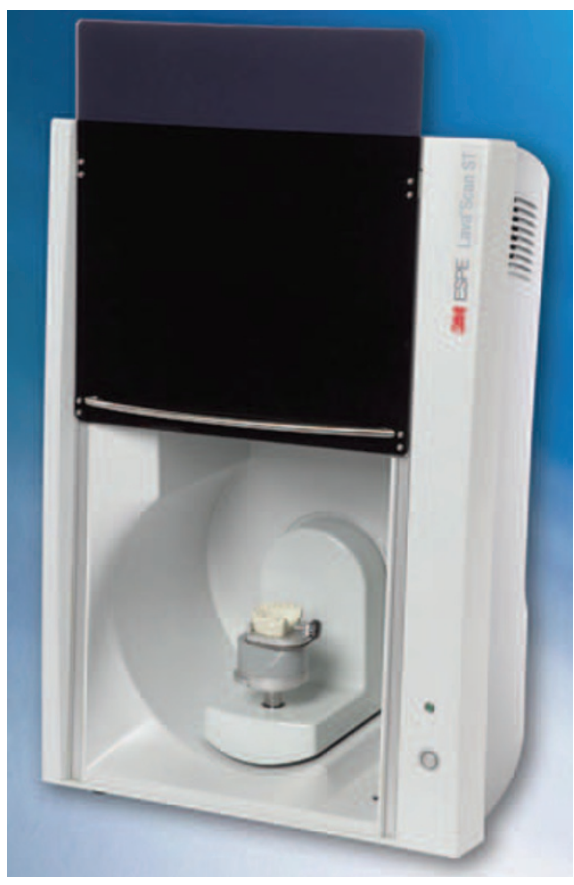

Fig. 1 A model mounted ready for scanning

graduation of 22 years) with practices in Alness (Scotland), Buxton and Liverpool (England), and Coleraine (Northern Ireland) were each asked to recruit ten patients requiring a fixed-fixed bridge, and complying with the criteria set out in Table 1.

Having had an opportunity to read and consider the patient's information sheet and having received satisfactory answers to any questions concerning the evaluation, each patient was asked to complete and sign a consent form.

The pre-operative status of the gingival tissues adjacent to the tooth/teeth to be restored was assessed using codes and criteria set out in Table 2. Appropriate vitality and radiographic assessments were completed where indicated, and the outcome recorded.

\section{Operative procedures}

Where clinically indicated, and with the approval of the patient, appropriate local anaesthesia was obtained. The tooth/ teeth to be restored were prepared using conventional instruments and techniques. The preparations had the following features:

- Rounded line and point angles

- Resistance and retention form achieved from remaining tooth tissues

- Shoulder of $1 \mathrm{~mm}$ at the gingival margin

- $2 \mathrm{~mm}$ occlusal clearance.

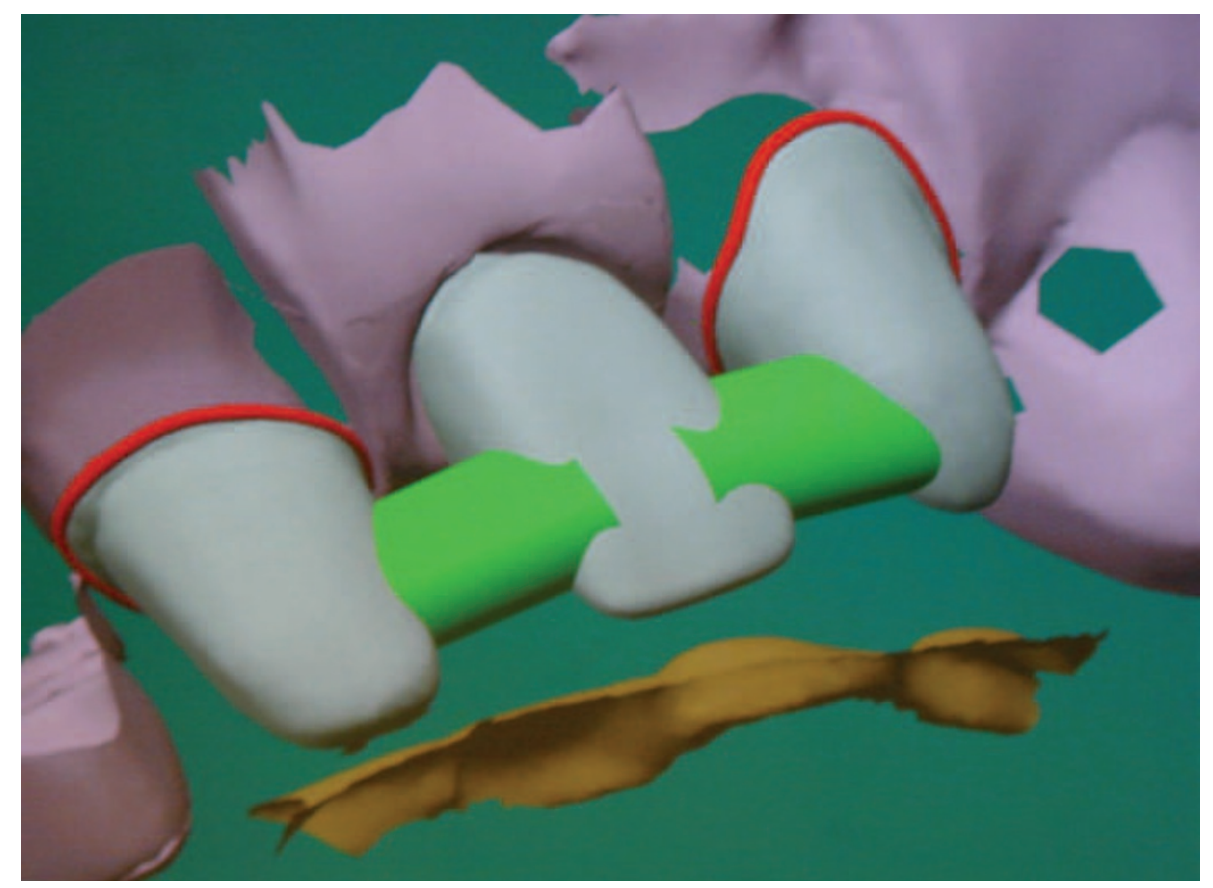

Fig. 2 Computer design for Lava framework

The tooth shade was selected using the VITAPAN (Vita Zahnfabrik, Germany) classical shade guide. An impression was then taken in vinyl polysiloxane (VPS) impression material, an opposing arch impression in alginate and bite registration if indicated. A temporary bridge was constructed and placed. Impressions were then sent to the laboratory designated for the study (Castle Ceramics, Tamworth, Staffs, UK).

\section{The laboratory procedures for the construction of Lava bridges}

Dies were cast in white plaster and the dies and models were mailed to $3 \mathrm{M}$ ESPE, Seefeld, Germany, for the construction of the zirconia substructure. With this system the casts, dies and bite registration wafer are scanned using a non-contact photo-optical recording from 11 directions and the digital information sent to the computer program for three-dimensional presentation on the screen (Fig. 1).

The bridge framework is designed on the computer within the parameters of the system, which sets the thickness of the framework $(0.5 \mathrm{~mm})$ and the square area of the bridge connectors $\left(9 \mathrm{~mm}^{2}\right)$. A library of pontic designs is stored as in the system and the connectors are designed using the information from the optical scanning (Fig. 2).

The three-dimensional design can be viewed from any direction and as part of the design process the wall thickness of the framework, and the thickness of the cement gap can be freely shaped. The framework is designed to allow for the shrinkage occurring during the final sintering process (40\% volume and 20$25 \%$ linearly). The final design is then sent to the milling machine, pre-loaded with appropriately sized blocks of the Lava Y-TZP material identified by a barcoded label carrying information on the exact shrinkage of each particular block. These blocks are formed using powder technology in which pure and fine Y-TZP powder is pressed to shape to give a homogeneous microstructure and lightly pre-sintered. These so-called 'green body' blocks can be loaded in

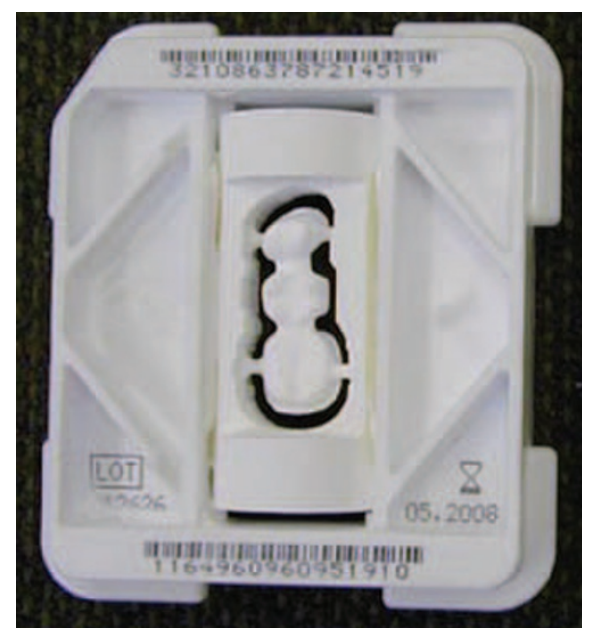

Fig. 3 Milled zirconia block 


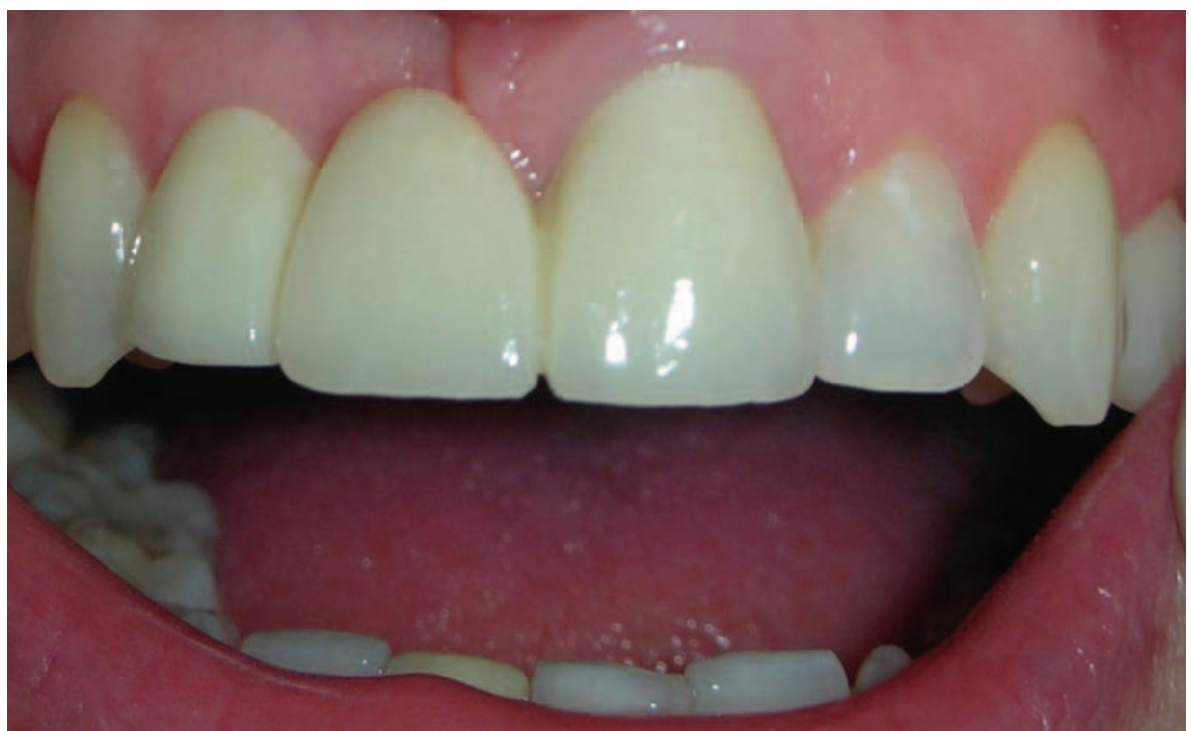

Fig. 4 3-unit Lava bridge, replacing UR1, at one-year

the milling machine, with the average 3-unit bridge taking approximately 50 minutes to mill (Fig. 3).

Prior to sintering, the milled block was trimmed and stained with one of seven dies to match the chosen shade(s) of the final restoration. It was then placed in the special sintering oven for an elevenhour automatic cycle, which reaches temperatures of up to $1,500^{\circ} \mathrm{C}$.

The completed frameworks were then returned to the UK laboratory for the addition to full contour of the special overlay ceramic, LavaCeram, which has a similar (low) coefficient of thermal expansion to zirconia. In the present study, the completed bridge was delivered to the clinician for placement approximately 17 days after the original preparation and impressioning.

\section{Placement of the Lava bridges}

Local anaesthesia was administered if indicated, the temporary bridge removed and the preparations cleaned with water spray. The bridge was tried in to check fit and occlusion, with any adjustment necessary being carried out using fine diamond burs under water coolant. Any such adjusted porcelain was repolished using a porcelain polishing kit prior to cementation. All the bridges in the trial were placed with the same self-adhesive resin-based luting system (RelyX Unicem, 3M ESPE, Seefeld, Germany) used in accordance with the manufacturer's instructions. When the luting material was polymerised, the occlusion was checked and maintenance instructions given to the patient. Before discharging the patient baseline assessment forms were completed (Table 2).

\section{Annual review of the restorations}

Each bridge was reviewed within three months of the first anniversary of its placement by a trained and calibrated examiner together with the clinician who had placed the restoration. The examiners completed an assessment form which was based on criteria laid down by Ryge $^{19}$ (Table 3) to evaluate the integrity of the restoration, its anatomic form, marginal adaptation, surface quality, sensitivity, the condition of the adjacent gingivae, and the presence or absence of secondary caries. Before the patient was dismissed a consensus opinion was agreed if the examiners ratings had differed. Photographic records of the restorations were also taken at the annual reviews (Figs 4 and 5). If any restoration was found to be defective, an adverse event form was completed and the necessary remedial work completed.

\section{RESULTS}

As of July 2006, a total 39 Lava bridges have been placed, the most recent being in June 2006. At the time of writing 38 Lava bridges (of mean age 12.3 months) in 33 patients ( 21 female, 12 male) from the four participating practices have been reviewed. The distribution of the reviewed bridges is recorded in Table 4. Thirteen of the bridges (all 3-units) replaced anterior teeth (Inci-

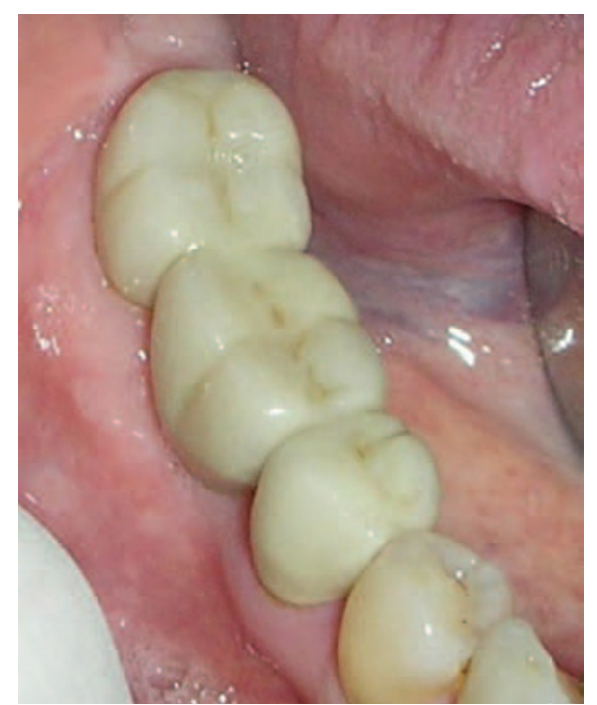

Fig. 5 3-unit Lava bridge, replacing LR6, at one-year

sors or canines) and the remaining 25 , including three 4-unit bridges, replaced premolars or molars.

All (100\%) of the bridges examined were present and 97\% $(n=37)$ of the bridges were intact. A small chip was detected in the veneering porcelain on the palatal surface of a premolar retainer, which was shaped to simulate a canine. The patient was unaware of any roughness and the practitioner was able to smooth and polish the defect.

Three patients (8\%) reported dull pain or sensitivity from the abutment teeth. In two cases this was two or three months after cementation and, after investigation, the offending abutment teeth were successfully endodontically treated. Each was a tooth extensively restored with an amalgam core prior to preparation. Access cavities had therefore been prepared in the occlusal surface of two molar retainers, but the Lava bridges were otherwise intact and performing well, and the final composite restorations were optimal when examined using the same Ryge criteria. The remaining patient complained of occasional sensitivity but this patient had generalised sensitivity from her teeth and the pain experience from the Lava bridge region was no different to the rest of her dentition.

Thirty-six (95\%) of the Lava bridges were scored as optimal for marginal adaptation. A slight catch with the explorer was detected on one margin of one of reviewed bridges. No secondary caries was detected. 


\section{Table 3 Modified Ryge criteria}

Anatomical form

$0=$ Restoration continuous with tooth anatomy

1 = Slightly under-or over-contoured restoration

Secondary caries

$0=$ No visible evidence of caries contiguous with the margin of the restoration

$1^{*}=$ Caries is evident contiguous with the margin of the restoration

Marginal adaptation

$0=$ Restoration is contiguous with existing anatomic form, sharp explorer does not catch

$1=$ Explorer catches, no crevice is visible into which the explorer will penetrate

$2^{*}=$ Obvious crevice at margin, dentine or lute exposed

\section{Surface roughness}

$0=$ Smooth surface

$1=$ Slightly rough or pitted

$2=$ Rough, cannot be refinished

Colour match

$0=$ Very good/good colour match, restoration almost invisible

$1=$ Slight mismatch in colour, shade or translucency

$2^{*}=$ Obvious/gross mismatch, outside the normal range

Gingival health: To be assessed adjacent

to the restoration

$1=$ Healthy gingivae

$2=$ Mild inflammation - slight color change, slight edema, no bleeding on probing

3 = Moderate inflammation - redness, edema and glazing, bleeding on probing.

$4=$ Severe inflammation - marked redness and edema, tendency to spontaneous bleeding

*unacceptable

At the one-year review the gingival tissues (when examined facially, mesially and distally) all showed an improvement in the scores for gingival health over baseline scores (Table 5).

Two (5\%) of the bridges examined showed a slight mismatch in colour but it was of no concern to the patients. In one case a slight mismatch was detected at cementation but at that time the patient was not concerned. Subsequently the patient returned and it was decided to replace the otherwise satisfactory bridge.

No staining was noted on any of the bridges examined. Also scored at the review was the anatomic form of the Lava bridges and this was scored as optimal in all cases.

\section{DISCUSSION}

The increasing demand for metal free restorations has coincided with the

\section{Table 4 Distribution of the bridges reviewed at one year}

\begin{tabular}{|c|c|c|}
\hline \multicolumn{2}{|c|}{ Tooth replaced (3-unit) } & Number \\
\hline \multirow{6}{*}{ Upper } & Central Incisor & 5 \\
\hline & Lateral Incisor & 7 \\
\hline & Canine & 1 \\
\hline & 1st Premolar & 6 \\
\hline & 2nd Premolar & 4 \\
\hline & 1st Molar & 7 \\
\hline \multirow{2}{*}{ Lower } & 2nd Premolar & 1 \\
\hline & 1st Molar & 4 \\
\hline \multicolumn{3}{|c|}{ Teeth replaced (4-unit) } \\
\hline Upper & 1st \& 2nd Premolars & 3 \\
\hline \multicolumn{2}{|l|}{ TOTAL } & 38 \\
\hline
\end{tabular}

Table 5 Comparison of gingival health at baseline and one year

\begin{tabular}{|l|l|l} 
& Baseline & One-year \\
\hline Facial & $85 \% 1,15 \% 2$ & $95 \% 1,5 \% 2$ \\
\hline Mesial & $82 \% 1,18 \% 2$ & $100 \% 1$ \\
\hline Distal & $85 \% 1,15 \% 2$ & $95 \% 1,5 \% 2$ \\
\hline
\end{tabular}

adaptation of CAD-CAM techniques and the availability of new all-ceramic materials for dental use. One of the materials in the forefront of this movement is zirconia, in the form of yttrium tetragonal zirconia polycrystals (Y-TZP). If this material is to be satisfactory both from the patients' and the clinicians' viewpoint then bridges formed in it must perform as well as bridges constructed in the well-established metal-ceramic materials, which have a reported survival rate of at least $85 \%$ at ten years, ${ }^{20}$ and improve upon the performance of other all-ceramic materials, such as alumina and lithium disilicate based ceramics, when used in bridgework. ${ }^{21,22}$

All the bridges examined at the firstyear review were present and intact, though one small chip of the veneering porcelain was detected and in two cases an abutment tooth had been endodontically treated through an occlusal access cavity. The small chip detected was on the palatal surface of a first premolar retainer, which was canine-shaped due to the absence of that tooth and the mesial migration of the first premolar (the bridge used a central incisor as the other retainer and replaced the missing lateral incisor). The patient was unaware of the chipping and the operator successfully polished the surface to a smooth finish. The chip was entirely contained within the veneering porcelain and was not a delamination to the Y-TZP framework. After discussion with the principal investigator it was decided that if any further cases of chipping of the veneering porcelain were detected a VPS impression would be taken of the chip and a model cast for SEM analysis to determine the cause. At the time of writing no other chipping has been detected in this trial though similar minor chipping has been reported in clinical trials of Lava, again in one case each, of similar numbers evaluated, in each trial ${ }^{15,23}$ and a trial of 59 Cercon $^{24}$ (Dentsply, Ceramco, Burlington, N J, USA) 3 and 4-unit fixed-fixed bridges reported a similar incidence. However, the issue of chipping in veneering porcelain is not unique to zirconia frameworks and is equally likely to occur when such porcelains are veneered on to other types of 
framework. In this respect, it has been reported that the veneering ceramic system used (Lava Ceram) possessed one of the highest microtensile bond strengths of any ceramic material, and was also one of the strongest core-veneer ceramics for use with zirconia, when tested in the laboratory. ${ }^{25}$

The two post-insertion endodontically treated abutments were molar teeth. Preoperative assessment of these teeth indicated that each had been heavily restored prior to preparation. In both cases there was persistent dull pain from the abutment that commenced approximately three months after cementation. After investigation and subsequent root treatment, restoration of the access cavity was completed and on review these cases were pain-free, the restorations rated optimal, and the bridges performing well. That cavities of a size to enable molar endodontics can be cut in retainers and that the bridges can continue to give good clinical service would seem to suggest that the strength of the zirconia-based material under evaluation is satisfactory. It has been reported that endodontically treated retainers, especially distal retainers, ${ }^{26}$ are a risk factor in the failure of bridge work but this has been shown not to be the case by Palmqvist and Schwarz. ${ }^{27}$ However, the bridges reviewed by these workers were not all-ceramic bridges and also had not been endodontically treated through the bridge framework so performance of these two cases will be closely monitored over the three-year trial period. Berganholt ${ }^{28}$ in his literature review has shown that iatrogenic injury to the dental pulp occurs with a frequency of 10-15\% over a period of 5-10 years and Jackson et $a l .{ }^{29}$ in their review of 603 crowned teeth in 103 patients with crowns or bridges found that 5.7\% required root canal treatment (RCT) over the four-year observational period. The incidence of RCT in the present study, with 76 abutment teeth, at one-year is $2.6 \%$ and as the preparation guidelines for Lava abutments are very similar to those of metal-ceramic materials it may be expected that the intervention rate over the full trial period $\mathrm{w}$ ould be similar.

The good health of gingival tissues adjacent to Lava bridges was commented upon by all the practitioners in the trial.
The scores evaluated at the one-year review (Table 4) confirmed the view that the zirconia-based material is very well tolerated by the soft-tissues with no allergic reactions reported. Only one bridge (3\%) evaluated at one-year was scored less then optimal for colour match. The patient, however, was unaware of a slight colour mismatch of this posterior bridge. As mentioned in the results, another bridge, which was more visible, was replaced on the grounds of a slight colour mismatch. It was an early case for the practitioner concerned and he usually preferred a different shade system to the Vitapan Classic guide (Vita Zahnfabrik, Bad Sackingen, Germany) used for Lava restorations. This cannot, however, be the total explanation as the patient involved had two bridges constructed at the same time, both replacing the upper second premolar, and the contra-lateral bridge was considered a perfect colour match. The process of colouring the milled zirconia framework prior to sintering completed bridge would appear to give excellent results from the aesthetic viewpoint. Lastly, the first-year review of the remaining bridge in the trial will shortly be completed and the two-year reviews have commenced.

The satisfactory results at this early stage for all the criteria evaluated appear to confirm the results already published for similar clinical trials of this zirconia-based all-ceramic.

\section{CONCLUSION}

At one-year the Lava bridges placed in this trial and reviewed to date were satisfactory.

\section{The support and construction of the Lava} frameworks, by $3 M$ ESPE, Seefeld, Germany is acknowledged. Thanks are due to Castle Ceramics, Tamworth, for the completion of the construction of all the Lava bridges. Thanks also to Mr Ian Taylor (Castle Ceramics) and Mr Laurie Littlejohn (Dental Technology Services, Glasgow) for their time and knowledge, enabling the authors to understand the laboratory processes.

1. Burke FJ T, McCord J F. Research in dental practice - problems and solutions. Br Dent J 1993; 175: 396-398.

2. Hopkins L M A, Eaton K A. Research in general dental practice - what is involved? Part 1. General considerations. Prim Dent Care 1996; 3: 71-74.

3. Jones C S, Billington R W, Pearson G J. The advantages and disadvantages of running a clinical trial in general practices. Br Dent J 2004; 197: 311-313.

4. Burke F J T, Crisp R J, McCord J F. Research in dental practice: a 'SWOT' analysis. Dent Update 2002; 29: $80-87$.
5. Wilson N F H, Mjör I A. Practice-based research: importance, challenges and prospects. A personal view. Prim Dent Care 1997; 4: 5-6.

6. Burke F J T, Wilson N F H. Introducing the PREP panel. Dent Pract 1994; 32: 30.

7. Crisp R J, Burke F J T. One-year clinical evaluation of compomer restorations placed in genera practice. Quintessence Int 2000; 31: 181-186.

8. Burke F J T, Crisp R J, Bell TJ, McDermott K et al. Two-year evaluation of restorations of a packable composite placed in UK general dental practices. BrDent J 2005; 199: 293-296.

9. Burke F J T. Amalgam to tooth-coloured materialsimplications for clinical practice and dental education: government restrictions and amalgam-usage survey results. J Dent 2004; 32: 343-350.

10. Dental Practice Board. Digest of statistics, 2002/2003. DPB, Eastbourne, UK.

11. Piconi C, Maccauro G. Zirconia as a ceramic biomaterial. Biomaterials 1999; 20: 1-25.

12. Sorensen J A. The Lava system for CAD/CAM production of high-strength precision fixed prosthodontics. Quintessence Dent Technol 2003; 26: 57-67.

13. Curtis A R, Wright AJ, Fleming G J P. Thee influence of surface modification techniques on the performance of a Y-TZP dental ceramic. J Dent 2006; 34: 195-206.

14. Curtis A R, Wright AJ, Fleming G J P. The influence of simulated masticatory loading regimes on the bi-axial flexural strength and reliability of a Y-TZP dental ceramic. J Dent 2006; 34: 317-325.

15. Pospiech $P$, Nothdurft F. A prospective study on the long-term behaviour of zirconia-based bridges (Lava): results after 3 -years in service. J Dent Res 2004; 83 (Sp Iss B): 0230

16. Nothdurft F P, Rountree P R, Pospiech P R. Clinical long-term behaviour of zirconia-based bridges (Lava): five-year results. J Dent Res 2006; 85 (Sp Iss C): 0312

17. Burke F J T, Crisp R J, Richter B. Handling evaluation of a self-adhesive universal resin cement by UK dental practitioners. Int Dent J 2006; 56: 142-146.

18. Koehler K, Sadan A, Burgess J O, Blatz M B. Resin bond to Lava zirconia intaglio surface. J Dent Res 2003; 82 (Sp Iss A): 1650.

19. Ryge G. Clinical criteria. Int Dent J 1980; 30: 347-357.

20. Scurria M S, Bader J D, Shugars D A. Meta-analysis of fixed partial denture survival: prostheses and abutment. J Prosthet Dent 1998; 79: 459-464.

21. Taskonak B, Sertgõz A. Two-year clinical evaluation of lithia-disilicate-based all-ceramic crowns and fixed partial dentures. Dent Mater 2006; 22: 1008-1013.

22. Olsson $K$, Fũrst $B$, Andersson $B$, Carlsson $G E$. A long term retrospective study and clinical follow-up study of In-ceram alumina FPDs. Int J Prosthodont 2000; 13: 131-135.

23. Raigrodski A J, Chiche G J, Potiket N, Hochstedler $J \mathrm{~L}$ et al. Clinical efficiency of Y-TZP based posterior fixed partial dentures. J Dent Res 2005; 84 (Sp Iss A): 0226

24. Bornemann G, Rinke $S$, Huels A. Prospective clinical trial with conventionally luted zirconia-based fixed partial dentures - 18 month results. J Dent Res 2003 abstract \# 842.

25. Aboushelib M N, Kleverlaan C J, Feilzer A J. Microtensile bond strength of different components of core veneered all-ceramic restorations. Part II: Zirconia veneering ceramics. Dent Mater 2006; 22: 857-863.

26. Roberts $D H$. The failure of retainers of fixed bridge prostheses. Br Dent J 1970; 128: 117-124.

27. Palmqvist $S$, Schwarz B. Artificial crowns and fixed partial dentures $18-23$ years after placement. Int J Prosthodont 1993; 6: 279-285.

28. Bergenholtz G. latrogenic injury to the pulp in dental procedures: aspects of pathogenesis, management and preventive measures. Int Dent J 1991; 41: $99-110$

29. Jackson C R, Skidmore A E, Rice R T. Pulpal evaluation of teeth restored with fixed prostheses. J Prosthet Dent 1992: 67: 323-325. 